Reilly, K. P., and K. M. Gulliver. 1992. Interstate authorization of distance higher education via telecommunications: The developing national consensus in policy and practice. The American Journal of Distance Education 6(2):3-16.

Michael G. Moore

\section{International Computer Conferencing for Professional Development: The Bangkok Project}

Terry Anderson and Robin Mason

Abstract

The Bangkok Project, which recently linked educational computer networks world wide, was a successful application of the new international electronic mail and computer conferencing networks to support professional development and reflection by members of the distance education community. This article discusses the Project's rationale and operational details. The authors conclude that this medium offers an exceptionally costand learning-effective means of providing inservice support to distance educators on a global scale.

Cervero (1990) has argued that the "reflective practitioner" does not need pre-formatted content materials as much as an opportunity to share and develop professional reflection within a community of peers. This sharing of experience and expertise is especially important for distance educators given the rapid expansion of distance education and the impact of information technologies on the production, organization, and delivery of distance education programming.

Professionals within the distance education community are few in number and spread across the globe. In order to meet the informationsharing, networking, and knowledge-dissemination needs of its members, the International Council for Distance Education (ICDE) sponsors a face-to-face conference approximately every three years. At these gatherings members of the community carry on formal and informal discussions and develop personal networks. Unfortunately, like all face-to-face encounters, this conference is restricted to those who can travel to a particular site at a particular time. Could the electronic networks be used as a vehicle for a complementary conference that would span barriers of time and distance, be affordable, and yet still provide the intellectual and social stimulation to develop and educate our community of distance education professionals? This was the question answered by the Bangkok Project. 


\section{Organizing the Project}

The Bangkok Project was an experimental project designed to link distance educators using all of the world's electronic networks. The Project developed and tested five prototype features: 1) support of at least two levels of interaction-local, community-specific interaction and general, network-wide interaction; 2) the use of "porters" to manage the interactions; 3) linkage to the face-to-face international conference; 4) a seminar format with separate session topics, each with a "host" and a "first speaker"; and 5) the use of the networks exclusively for organization and promotion.

Spanning the Networks. The Bangkok Project used the distribution function of the Internet, a collection of over 1,3 I3,000 networked computers in fifty-five countries around the globe (Network Information Systems Centre 1993). Despite the immense size of Internet and its rapid growth rate (nearly 2000 host computers added daily), there are many hundreds of additional networks and stand-alone systems that are not directly connected to the Internet, but that have capacity for linkage through various Gateways (e.g., Bitnet, Fido Net, KI2 Net). Global connectivity across these networks is hampered because many users are restricted in their technical capacity or knowledge of networking to the particular mail or conferencing system to which they normally subscribe. To alleviate this problem the Bangkok Project attempted to provide access to all members of the international community without requiring them to leave their familiar local computer system or to obtain additional passwords or access to new computer systems. We wanted the process of bringing the Bangkok Conference to the user to be as transparent as possible.

In order to accomplish this linking of networks, a central mail distribution list was established at the University of Calgary in Canada. All conference messages were posted to this central list, from which they were fed to approximately twenty-five different networks or mail discussion lists for further distribution (see Appendix $\mathrm{C}$ for a list of participating networks and lists).

Managing the Interaction. The recipients of the main conference postings were volunteer "porters," the "unsung heros of the network nation" (Netweaver 1991). The porters' task was to copy electronic messages from one system to another in order to expand the number of recipients. They were given the power to edit messages to ensure that interaction that was "ported" across was relevant and of potential use to their network users. Porters then remailed or posted the messages to their own networks. Porters were also responsible for monitoring their networks for responses that could be "ported" back to the main Calgary mail list for distribution across the full Bangkok Project. Again, porters were empowered to select only those messages that they believed were of interest and relevance to the many thousands of readers on the full project network.

The contribution of these human "filters" ensured that the widely distributed interactions were legible, relevant, and reflective of a minimal level of network etiquette. Some porters developed sophisticated relays to automate this process. The results were very encouraging; unlike many widely distributed network mail discussions, the Bangkok Project was characterized by an almost complete absence of irrelevant or mismailed items.

Linkage to the Face-to-Face Conference. The ICDE conference serves as a focal point for interaction within the distance education community. The Bangkok Project was designed to build upon and enhance the face-to-face interaction at the 1992 Conference through integration with the meeting in Bangkok; topic areas were chosen to complement themes of this face-to-face conference. The Bangkok Project began four weeks before the XVI World Conference and ended two weeks after its completion. The electronic conference was designed to provide an introduction to issues that could be further explored in the face-to-face sessions and as a forum for reflection and comment once face-to-face delegates returned home. The Bangkok Project also attempted to share the excitement and the social and intellectual stimulation of the World Conference with the vast majority of distance educators who could not afford the time or expense of traveling to Bangkok.

The Project worked to establish a site in Bangkok so that delegates could experience this type of interactive, electronic communication; could review items and interactions during the weeks preceding the conference; and could interact with the larger community of electronic participants during the conference. Unfortunately, the computer conference site in Bangkok was never established due to logistical and communications problems. Despite the offer from Softwords Research International of a CoSy computer conference system and the offer by IBM Thailand of micro computers to be used as terminals in Bangkok, the conference organizers were not able to provide the necessary network connection, space, or human resources needed to support the site. Ironically, less then seven days after the decision by the conference 
organizers to cancel on-site support, the first Thailand connection to the Internet was announced. This site could have provided the necessary electronic connectivity to support the project.

Because of this logistical failure, the capacity to integrate face-to-face and computer conferencing was not tested in this project. The development of "real time" interaction capacity on the international networks opens the possibility for synchronous as well as asynchronous communications between delegates attending conferences face-to-face and those in different areas of the globe. Technologically supported communication may never completely replace face-to-face contacts for either formal education or professional development. However, our experiences as distance educators have shown that meaningful interaction and learning can and does occur outside of the confines of time and space.

\section{Conference Format}

Sorensen (1992) points out the necessity to use concepts and terminology from familiar domains as metaphors to understand and use new communications systems. The Bangkok Project used the metaphor of the small group presentation common in face-to-face conferences. The project was divided into six separate topics. Each topic was discussed for approximately two weeks, and two topics were presented simultaneous-

ly. One topic extended throughout the seven weeks of the project to test the value of longer-running conferences.

A volunteer host was assigned to each topic. The host introduced the first speaker, provided occasional summary comments, and helped stimulate or restrain the interaction as necessary.

Six internationally known experts in distance education were invited to serve as first speakers (see Appendix A for first speaker names and for titles of the six topics). The procedural guidelines provided to the first speakers were purposely vague to allow development of particular styles of interaction within each topic. Each first speaker submitted opening remarks consisting of three to five screens of text that described emerging issues and ideas relevant to the session topic. One first speaker also submitted a longer, journal-type article to stimulate discussion.

Support for Multi-Level Interaction. The twenty-five participating networks or distribution lists (see Appendix C) had markedly different interests and geographic mandates. Some (e.g., Usenet-Alt.

Education.Bangkok.) were distributed to approximately 50,000 computer systems around the globe, others to stand-alone systems within a single college or university. On the smaller systems, interactions could stimulate local reactions or special group communication parallel to interactions with the larger discussion topic. This dual level of interaction allowed those interested in a particular item of discussion or from a particular geographical area to carryon a side conversation of specific interest to these members. In face-to-face format, of course, such side conversations would be disruptive and generally perceived as reflecting very poor form. The porters were able to filter these secondary conversations and carry back to the main discussion any conclusions, insights, or questions from the first speaker or other participants. Although this second-level discussion was supported during the Bangkok Project, many networks reported few interactions at this level. Perhaps a prohibition against such side conversations might have been inferred from the seminar metaphor, thus inhibiting such interchanges.

The Networks as Orf?anizational Tools. The Bangkok Project was organized exclusively through interaction on the various electronic networks. An organizational conference was established early in the project at the University of Calgary. The authors of this article served as Network Coordinator and First Speaker Coordinator, respectively. The organizational group consisted of these two coordinators, approximately thirty-five porters, and another group of twenty interested supporters. All promotion, recruitment of facilitators, and conference administration was done on the networks. The project concluded with a two-week evaluation conference in which organizers shared their suggestions for improving future conferences.

The direct costs to the participants and to the organizers of the Bangkok Project were extremely low, even taking into account the hidden and infrastructure costs of using the international networks and the contributions in time and personal energy provided by the many volunteers and their respective employers. The Bangkok Project received no funding from any sources and charged no fees to participants, yet the out-of-pocket expenses to the organizers were less than $\$ 100.00$ ! This cost compares favorably to the thousands of dollars that participation in international face-to-face conferences costs each participant.

A final benefit of using electronic conferencing for administration of this type of project is the resulting electronic record or log of all interactions between the organizers. This record provides an invaluable archive that can guide future network organizers and researchers. The transcripts of the organizational conference as well as the transcripts of all six 
topics are available free of charge through file transfer programs available on the Internet (see Appendix B).

\section{Content of the Bangkok Project Conferences}

The technical success of this experiment, given its complexity and innovative nature, is ample justification for issuing a report on which others can build in subsequent applications. However, a network is only as good as the content that it carries. What was the value of the Bangkok discussions? This analysis will discuss the nature and quality of the interactions in the conferences and conclude with lessons learned from the entire experiment.

Use of'the Conf'crences. There was considerable variation in the development of the six conferences. These differences were partially due to the order in which they occurred; for example, the last conference suffered from a lack of impetus both because it was last and because it came after a break during the actual meeting in Bangkok. However, other conferences suffered similar problems, the reasons for which are not as obvious.

Appendix B lists the number of messages for all conferences: 242 (not counting those used for conference organization) over a seven-week period. However, the quantity of messages in no way reflects the number of people who read and were stimulated by the discussions. This difficulty in estimating extended use is always a problem with computer conferences, but especially with the Bangkok Project, for which the potential audience was vast. Examples of the extended use of the discussions were provided by feedback messages such as the following:

I would like to respond to Kathy Kothman's post about portering on TENET, the relatively new state-wide network for public school educators and students in Texas. I was one of the lurkers through most of the conference. Kathy did a wonderful job of moving the material onto a newsgroup on TENET ! was more than just a little excited to find the conference. Michael Moore's wonderful first speaker discussion was stunning. And I was hooked. I lurked because I didn't have the knowledge base, and I was completely ignorant of CMC as practiced ! believe that this has been as stimulating and engrossing as my first long foray into a University library. (D. Perkins, Organization of the Bangkok Project Conference)
Another participant reported that she took printouts of the strategic planning conference to a management meeting at her institution because the issues addressed were relevant to the discussion there. Excerpts from several messages were read out by one participant giving a keynote address at a conference in the United Kingdom. Several courses on distance education and electronic communications used the conferences as part of the course material and, in some cases, students contributed queries and points of view. It is impossible to quantify or measure the level of extended conference participation. However, these examples suggest that the interactions on line are but the tip of an iceberg: many additional levels can be found below the surface.

Curiously, the overall rate of messages to the Bangkok Project reflected the optimum comfort level: approximately three or four per day. This rate seems to be a comfortable one for most people in coping with the physical messages, engaging intellectually with the material, and feeling that they are not being psychologically overwhelmed. A technical problem that sent hundreds of repeated messages all around the system occurred at the end of the first week. Fortunately, these error messages were delivered only to the porters, who were able to filter them out before they were distributed to end users. This potentially catastrophic error showed by contrast how appropriate the sustained level of messaging was to all concerned. The unpredictability of messaging created a certain amount of anticipation beforehand: "Well, here we go. I feel like someone standing on the top of a mountain and shouting, without knowing if anyone is listening!" (Tony Bates, Strategic Planning in Distance Education Conference). Another first speaker said he was preparing himself for anything between zero and one thousand messages. In actuality he received fifty messages over a two week period, probably a comfortable level of activity. Perhaps conferencing is, to some extent, a self-regulating mechanism in which people collectively match the contributions to the tolerance level.

For many contributors, the conference messages appeared as personal mail-they did not $\log$ on to a host system or a local confereneing subsystem to read the discussions in a conference. Few inputs were received from those who did access the discussions from conferencing systems such as UseNet Newsgroups and Fido Net Echos. Mail messages are undoubtedly more attention-demanding than conferences that the user has to make a special effort to access each time. 


\section{Contributors to the Conference}

Although about ten participants contributed messages to several conferences, most people contributed only one or two messages to one particular discussion. The actual number of contributors to the six conferences is also somewhat difficult to determine. Many messages were not signed, some participants used someone else's ID to send their messages, some headers did not contain names, and some messages were signed by several people. Nevertheless, it is apparent that messages came from various participants in at least twenty states of the United States, from five different sites in Canada, from several parts of Australia and the United Kingdom, and from New Zealand, Norway, and Venezuela. Although the distribution was global, the active participation should perhaps be described as international, since there rarely was participation by those in Third World countries.

A number of reasons could be hypothesized for the lack of participation from Third World distance educators. First, potential participants in Third World countries are more likely to have limited access to local hardware and international connectivity. Educational programming, at all levels and using all delivery modes, is done under severe economic constraints, and professional development activities and equipment for staff are but two of many competing needs. Second, although the Internet is a global network, the majority of host sites $(71 \%)$ are located in the United States. This imbalance is likely to continue for some time, in spite of the fact that percentage growth rates of Internet sites are higher in other countries than in the United States (Network Information Systems Centre 1993). Third, the use of a single language for interaction presents problems for those not comfortable with that language; they may be reluctant to expose themselves, through their writing, to a large, international audience. The use of porters as translators and editors could alleviate this problem, but adds complexity and time delays to the interaction process.

Fourth, the seminar style of presentation, with world-renowned experts as first speakers, probably inhibited novice users and inexperienced distance educators. There may also be a cultural component to this inhibition; some cultures discourage active questioning/debate and emphasize respect and listening (as opposed to discussion) with teachers and elders. Finally, participation in a fast-moving, technologically mediated environment may be influenced by both cultural and individual learning style factors. The two-week format of each discussion gave little time for reflection. Often readers were presented with comments, questions, and rebuttals seconds after reading the original posting. Although highly stimulating, this rapid information flow can induce a "read on" as opposed to "think on" mode of reception, which can be inhibiting to those who prefer reflective learning situations. The relationship between these hypothesized factors and participation in global electronic discussions warrants a great deal of further investigation.

Nature of the Interactions

Despite the number of "one-off' contributors (those who made only one contribution), there was a remarkable degree of interaction in the various conferences. Contributors responded to specific issues raised by previous participants. After the initial introductory messages from the first speakers to outline areas for discussion, there were no monologues or long harangues by people promoting their personal viewpoints or biases. The interactions were dialogues-sometimes between participants and the first speaker, sometimes between various participants.

Perhaps the most sustained and stimulating discussion centered on the value of interaction in distance education. Various perspectives on this issue were given by half-a-dozen participants, and the first speaker continued to refine and focus the inputs. In this and other discussions, reference was made to the relevant literature, to experience and applications, and to particular research. These were academic debates, not free-for-alls in which people made uncontrolled, personal comments. Given the heterogeneous nature of the participants, this positive outcome of the discussions-worthwhile, electronic dialogue on an international scale-is remarkable.

One of the factors that undoubtedly contributed to the disciplined nature of the interactions was the formal structure within which the conferences were set. First speakers were introduced and time frames for each discussion were given at the outset and adhered to, just as in a faceto-face conference. Participants were reminded by the hosts of conferencing etiquette: keeping messages short, relevant, and unambiguous. The whole project was elegantly managed from Calgary with informative and friendly messages that kept the whole experiment moving forward smoothly. Altogether, these measures created a strong sense of a sociable, but structured, environment.

The goal of sustained, academic debate was not uniformly met. All of the first speakers tried to cover too many issues, given the short time and 
the tangential nature of computer conferencing. One or, at most, two issues would have been appropriate for the time frame. Most discussions were caught in side issues, although the lively debate in Moore's conference on distance education theory did focus well on the nature of educational theory. The conference on databases never engaged in the central issues put forth in the stimulating opening messages by the first speaker. The conference on strategic planning got off to an excellent start in the first week, but lost its focus in the second week when the first speaker was interrupted by the technical problem referred to earlier and could no longer access the conference. The research conference was a microcosm of the whole: it comprised substantive discussion about distance education research, simultaneous comments about various side issues, and some continuation of issues from the earlier two conferences.

The conference on the use of computer-mediated communications (CMC) in developing countries, which ran the length of the whole project, provides a useful contrast to the two-week conferences. The original aim was to exploit the global nature of the experiment by encouraging participants to list all known applications of CMC in developing countries. This exercise proved to be a total failure, yet, over the seven-week period, the participants eventually discovered what they did want to discuss: impediments to the use of computer conferencing in all parts of the world. Some interactive discussion finally occurred toward the end of the period. This conference would not have worked in a twoweek timespan, yet it was more dispersed and unfocused than were the two-week conferences.

How to focus discussions is an important issue. Opening messages with many wonderfully stimulating questions seemed to overwhelm contributors and produce discussions on side issues. However, as these six examples show, it would be difficult to draw definitive rules about what works and what does not, except with hindsight. In the context of this experiment, three weeks per discussion might have worked better; each conference needed some "start-up" time and there were varying delays in relaying messages between the originators' home systems, the Calgary distribution link, and other sites or networks. However, the seven-weeks time frame could not have been extended without considerable loss of momentum.

\section{Conclusions}

We have learned a number of lessons from this project, and yet are left with a number of unanswered questions. We can see that projects of this sort need an effective conference structure; a tight focus to each discussion; human, rather than automated, filters; and a dynamic and committed group to promote and manage it.

Questions still needing answers include

Should subsequent projects use the same networking procedures?

Should online discussions be based on the face-to-face conference?

Should several parallel discussions run concurrently?

How can online discussion be promoted more widely to encourage increased participation?

The project showed that electronic networking can provide cost-effective, yet meaningful, interactions among distance education professionals. The list of participants showed that current access to or awareness of the technology is generally limited to distance educators in the more technologically developed countries. The growth of electronic communications in all countries will continue to expand accessibility and the potential for truly global networking. The Bangkok Project experimented with structures and organizational systems that used the power of new technologies as well as the expertise of the professional distance education community. Some aspects of this technology and its application can and will be improved in subsequent projects. Distance educators have an obligation to be in the forefront of the development of this technology. As proponents for increased educational access and quality, we cannot afford to ignore the application of these powerful new global communications technologies to both our needs as reflective practitioners and to the needs of learners in general.

The field of distance education is developing in many diverse directions. The application of interactive communications technologies can significantly increase the quantity and quality of debate, information exchange, and personal networking that distinguishes our professional organizations. The Bangkok Project, which has demonstrated that the tools for cost-effective, professional development programming already exist, presents a dual challenge: first, development of programming that meets the needs of our distance education community, and second, technological development that ensures that all members of our global community have access to this medium. 
Cervero, R. 1990. A model of professionals as learners. In Visions for the Future of Continuing Professional Education, eds. R. Cervero and J. Azzaretto, 161-82. Athens, GA: University of Georgia.

Carlson, L. 1991. Netweaver. (Newsletter of the Electronic Networking Association. )

Network Information Systems Centre. 1993. SRI International Internet Domain Survey. January.

Sorensen, E. K. 1992. Metaphors and the design of human interface. In Collaborative Learning Through Computer Conferencing, ed. A. Kaye, 189-200. Berlin: Springer-Verlag.

\section{Appendix A. Discussion Topics and First Speakers}

1. Applications of Electronic Communication for Distance Education in the Third World

Dr. Robin Mason, Lecturer, Open University of the United Kingdom

2. Emerging Theories and Philosophy of Distance Education Dr. Michael G. Moore, Director, The American Center for the Study of Distance Education

3. Strategic Planning and Policy for Distance Education Dr. Tony Bates, Director of Research, Open Learning Agency of British Columbia

4. Emerging Issues in Distance Education Research

Dr. Gene Rubin, Editor, Research in Distance Education,

Athabasca University

5. Databases and Documentation for Distance Education Mr. Laury Melton, International Centre for Distance Learning

6. Distance Education and Student Support

Dr. David Sewart, President, International Council for Distance Education
Topic Name

Items Length (Bytes) File Name

Introduction and Overview

4

21273

introduction

Computer Mediated

Communications

61

107387

cmc.trans

Database Use in

Distance Education $\quad 26 \quad 41979$ database. trans

Strategic Planning in

Distance Education $41 \quad 85621$ planning. trans

Research Issues

Student Support

Theory and Philosophy

Organization of the

Bangkok Project

$50 \quad 99221$

$10 \quad 31134$

$50 \quad 224176$

research. trans

support. trans

theory. trans

$121 \quad 265904 \quad$ organization. trans

These files are available for anonymous ftp from the ftp site at the University of Calgary.

Site Name: FTP.ACS.UCALGARY.CA Directory:

jpubjprivate $\sim$ roup _info/icdej

To access: ftp to the above site; $\log$ in as "anonymous"; use your EMAIL address as the password; cd to the above directory and get the file(s) of interest. For more detailed FTP instructions consult any introductory text covering Internet services.

Appendix C. Participating Networks and Lists

\author{
AEDNET \\ AGSAT \\ Capital Area Researchers in EdTech \\ Distance Education Online Symposium \\ EduTel \\ FidoNet Echos EDUCATOR, High_ED \\ GLOSAS-L \\ IUNK \\ Interpersonal Computer and Technology List \\ K12 Net, UseNet K12 \\ KIDSNET, COSNDISC
}


Lancaster University, NIX

NISS Bulletin Board

Nursing-I, ETNet. Newedu-l

NYSERnet

Open University of UK

ShareNet

Sigtel-1

TENET

Unibase Educators Network

University of Alberta

University of Calgary

U senet - Alt.Education.Bangkok

Venezuelan Academic Network

VETMED, VETLIB

\section{Acknowledgements}

The authors would like to thank the porters, hosts, and first speakers, and the computer services staff at many sites, especially the University of Calgary site. Without the considerable efforts of these volunteers this project would not have succeeded. The authors also would like to acknowledge the valuable contributions of Ken Borland, past editor of DEOSNEWS and DEOS-L and currently Assistant Professor of Adult and Continuing Education at Dallas Baptist University, to our discussion of barriers to participation by Third World distance educators.

\section{Attitudes of Higher Education Faculty Toward Distance Education: A National Survey}

\author{
Tom Clark
}

\section{Abstract}

\begin{abstract}
Although distance education is growing in importance in the United States, little research has focused on the attitudes of American college and university teachers toward college-level distance education and toward the use of specific media in distance education provision. The attitudes of both participating and nonparticipating faculty toward distance education need further examination, since teaching innovations cannot succeed without their support. This study examines the receptivity to college-credit distance education of faculty members in two- and four-year higher education institutions. The research questions focused on general receptivity to distance education, the relationship between professional characteristics and attitude toward distance education, the connection between previous distance education experiences/ familiarity and receptivity, and on attitudes toward different distance education media and methods.
\end{abstract}

\section{Introduction}

Recent evaluation studies of distance education projects and activities have included surveys of the attitudes of participating faculty (cf. Burnham 1988; Dillon 1989; Spondor 1990). Studies of the attitudes of f culty toward distance education include a national survey of graduate IIbrary and information science faculty (Barron 1991), a comparative study of faculty attitudes toward distance instruction in land grant universities (Bankirer 1987), a study of faculty attitudes toward satellite-based instruction at member institutions of the League for Innovation in Community Colleges (Bunting 1989), and a comparative study of attitudes toward distance education held by instructors with previous distance education experience and instructors with no previous experience (Stinehart 1987).

Like earlier studies of nontraditional and external degree programs that reported either negative attitudes on the part of nonparticipating faculty (Stetson 1979; Patton 1975; Medsker and Associates 1975), or more 